\title{
Physicochemical and sensory properties of reduced-fat mayonnaise formulations prepared with rice starch and starch-gum mixtures
}

\author{
Pradeep Puligundla, Yong-Hwa Cho, Young-Tack Lee* \\ Department of Food Science and Biotechnology, Gachon University, Seongnam 461-701, Korea
}

\section{A B S T R A C T}

\begin{abstract}
As consumption of high-fat, high-calorie diets is directly linked to obesity and related health risks, low-fat or reduced-fat food production has received greater attention in recent years. In the present study, we determined the characteristics of reduced-fat mayonnaises that were formulated by partial substitution of oil using native and modified rice starches as well as starch-gum mixtures. Rice starch gels were substituted in the range $10-50 \%$. Substitution up to $20 \%$ of total oil was found desirable using both native and modified, hydroxypropylated and cross-linked hydroxypropylated, starch gels. Compared to full-fat control, superior sensory characteristics were observed for rice starch substituted mayonnaises. Starches increased the freeze-thaw stability of reduced-fat mayonnaises significantly $(p<0.05)$, especially using modified rice starches. Co-addition of either guar or xanthan gum and rice starch has no adverse effect on the physicochemical and sensory characteristics of the formulated reduced-fat mayonnaises.
\end{abstract}

Keywords: Reduced-fat mayonnaise; Rice starch; Freeze-thaw stability; Sensory characteristics; Viscosity

\section{INTRODUCTION}

Mayonnaise is an oil-in-water emulsion, traditionally prepared by emulsifying a substantial amount of oil/fat using egg yolk, which contains a number of emulsifiers. Besides fat, commercial mayonnaise typically contains egg yolks, salt, vinegar, thickening agents, and flavoring materials (Mun et al., 2009). It is generally regarded as a high-fat and high-caloric food owing to its higher content of oil, usually more than 65\% (Su et al., 2010). However, nowadays, consumers are more concerned about overconsumption of certain types of lipids, especially cholesterol and saturated fats. Concerns are primarily due to the fact that occurrence of several chronic diseases, such as obesity, cardiovascular diseases and cancer is positively correlated to the amount and type of fat consumed (Weisburger, 1997). Consequently, food manufacturers/researchers have begun exploring various ways to produce mayonnaise with a healthy image. The development of fat-free or reduced-fat mayonnaise is one such way.
However, complete elimination of oil or fat in mayonnaise is detrimental to its quality and stability. Fats play several functional roles in food emulsion. They significantly contribute to the appearance, flavor, texture, and shelf life of food emulsion (Nikzade et al., 2012; Worrasinchai et al., 2006). Therefore, the development of mayonnaise having reduced-fat or low-fat is of prime importance for the food industry at present.

On the other hand, several qualities (fat-dependent) of conventional mayonnaise cannot be replicated as easily in reduced-fat mayonnaise (Su et al., 2010). Low-in-fat o/w food emulsions such as reduced-fat mayonnaise often undergo creaming (or sedimentation) that contribute to the instability of an emulsion (Lorenzo et al., 2008). Different non-fat biopolymers, such as gums, starches, and proteins are often incorporated into fat-reduced products to replenish some of the fat functional attributes (Mun et al., 2009; El-Bostany et al., 2011).

To improve creaming stability in low-in-fat o/w food emulsions, polysaccharides are usually added to the aqueous

\footnotetext{
*Corresponding author:

Prof. Young-Tack Lee, Department of Food Science and Biotechnology, Gachon University, Seongnam 461-701, Korea,

Tel: +82-31-750-5565, Fax: +82-31-750-5273, E-mail: ytlee@gachon.ac.kr
} 
phase (Quintana et al., 2002). Starch, particularly modified starch is preferred in the formulation of reduced-fat products because of its inexpensiveness, tastelessness and the unique creamy texture that it imparts to products (Cho et al., 1999; Thaiudom and Khantarat, 2011). As a thickening agent, modified starches have been used for preventing phase separation during the storage of mayonnaise (Mun et al., 2009; Cheung et al., 2002).

Stability of mayonnaise is considerably reduced when the amount of oil is reduced (Lee et al., 2013). In order to achieve high emulsion stability of mayonnaise, several investigators used proteins with emulsifiers and gums such as xanthan and guar gums (Nikzade et al., 2012; Bortnowska and Tokarczyk, 2009). In commercial formulations, xanthan gum is frequently used as fat substitute, both alone in mayonnaise and together with starch in salad dressings (Mun et al., 2009). Magnitude of elastic modulus and complex viscosity of mayonnaise have been shown to be increased with the increase of oil or xanthan gum concentrations (Ma and Barbosa-Canovas, 1995). Gums modify the rheology of starch pastes by contributing the gum viscosity to the system (starch-gum-water) viscosity (Weber et al., 2009). To make low-fat mayonnaise with a texture close to that of traditional one, fat substitutes can be chosen in specific quantities (Liu et al., 2007).

Incorporation of the mixture of xanthan/guar gum hydrocolloids to low-in-fat $\mathrm{o} / \mathrm{w}$ emulsions has extended their stability significantly (Lorenzo et al., 2008). Blends of hydrocolloid and starch-based ingredients can be used to improve texture and mouthfeel of low-fat products (Pszczola, 1999).

Although rice is an important cereal that is available globally for human consumption, rice starch is scarcely used as a fat replacer in foods. The size of rice starch granules is similar to those of fat globules; hence, they can be preferred to provide a creamy texture to foods (Lee et al., 2013). To date, only a couple of studies have investigated reducedfat mayonnaise formulation using gelatinized rice starch/ xanthan gum (Lee et al., 2013), and enzyme ( $4 \alpha$ GTase)modified rice starch/xanthan gum (Mun et al., 2009). However, to our knowledge, there are no studies focusing on application of native and chemically modified rice starch for reduced-fat mayonnaise formulation. Therefore, the objective of present study was to determine the suitability of native and chemically modified (hydroxypropylated and cross-linked hydroxypropylated) rice starches alone or along with gums (guar and xanthan) for formulation of reduced-fat mayonnaise. Starch suitability was assessed by characterizing respective reduced-fat mayonnaise formulations in terms of physicochemical, freeze-thaw stability and sensory properties.

\section{MATERIALS AND METHODS}

\section{Materials}

All ingredients used to prepare the mayonnaise, such as soybean oil, eggs, vinegar, sugar, and salt were purchased from a local grocery store. Guar and xanthan gum were obtained from Jupiter International Co., Ltd. (Seoul, Korea).

\section{Preparation of native and modified rice starches}

Rice starch used for this study was isolated according to a traditional alkaline extraction method (Yamamoto et al., 1973). Native rice starch was chemically modified by both hydroxypropylation and dual modification of crosslinking and hydroxypropylation. Hydroxyproplyated (HP) rice starches were prepared according to the method reported by Wootton and Manatsathit (1984) with slight modification. Rice starch (500 g, dry basis (db)) was dispersed in distilled water $(700 \mathrm{~mL})$ containing sodium sulfate ( $8 \%$, starch basis (sb)). After adjusting to $\mathrm{pH} 11.5$ with $1 \mathrm{~N} \mathrm{NaOH}$, propylene oxide $(5 \%$ and $10 \%$, sb) was added to the dispersion using syringe with stirring at $45^{\circ} \mathrm{C}$ for $2 \mathrm{~h}$. The mixture was adjusted to $\mathrm{pH} 6.0$ with $1 \mathrm{~N} \mathrm{HCl}$. The samples were washed thrice with distilled water and once with ethanol, and then dried at $40^{\circ} \mathrm{C}$ overnight. For cross-linked and hydroxypropylated (CLHP) starches, the method of Choi et al. (2011) was used to modify. Briefly, dual-modified rice starches were prepared from rice starch $(500 \mathrm{~g}$, db), water $(700 \mathrm{~mL})$, sodium sulfate $(8 \%, \mathrm{sb})$, and phosphorus oxychloride $(0.02 \%, \mathrm{sb})$ under alkaline condition $(\mathrm{pH} 11.5)$ at $45^{\circ} \mathrm{C}$ for $2 \mathrm{~h}$. The mixture was added to propylene oxide $(5 \%$, sb) and stirred at $45^{\circ} \mathrm{C}$ for $24 \mathrm{~h}$. The $\mathrm{pH}$ of the slurry was adjusted to $\mathrm{pH} 6.0$ with $1 \mathrm{~N} \mathrm{HCl}$. The samples were washed thrice with distilled water and once with ethanol, and dried at $40^{\circ} \mathrm{C}$ overnight.

\section{Mayonnaise preparation}

Typical composition of full-fat mayonnaise is given in Table 1. Initially egg yolk was mixed by a blender ball and stirred for 30s in a Kitchen Aid mixer. Then all other ingredients (including sugar, salt, vinegar, rice starch, and gum gels) except soybean oil were added and stirred homogeneously for $1.5 \mathrm{~min}$. Finally soybean oil was added very slowly at intervals of 40 s with stirring for $4 \mathrm{~min}$.

Table 1: Formulation for full-fat mayonnaise

\begin{tabular}{lcc}
\hline Ingredients & Oil wt. basis (\%) & Amount (g) \\
\hline Soybean oil & 100 & 200.0 \\
Egg yolk & 14 & 28.0 \\
Salt & 0.75 & 1.5 \\
Sugar & 5 & 10.0 \\
Vinegar & 10 & 20.0 \\
Total & 129.75 & 259.5 \\
\hline
\end{tabular}

Emir. J. Food Agric • Vol 27 • Issue 6 • 2015 
For reduced-fat mayonnaise formulation, rice starch gel $(15 \%, w / v)$ was used to replace the oil, at levels of $10 \%, 30 \%$, and $50 \%$. For the formulation of reduced-fat mayonnaise containing guar or xanthan gum, gum (added at a level of $10 \%$ ) was initially prepared in the form of gel $(2 \%, \mathrm{w} / \mathrm{v})$ by dissolving in distilled water.

\section{$\mathrm{pH}$ and color measurement}

$\mathrm{pH}$ and color values of mayonnaise samples were measured at room temperature using a $\mathrm{pH}$ meter and a Minolta colorimeter CR-400 (Konica Minolta Business Technologies, Inc), respectively.

\section{Viscosity measurement}

Viscosity measurements were performed with a Brookfield viscometer RVDV-II+ with cone and plates with diameter of $25 \mathrm{~mm}$.

\section{Freeze-thaw stability}

Fifteen grams of mayonnaise sample $\left(\mathrm{F}_{0}\right)$ was transferred into plastic centrifuge tubes and then frozen at $-18^{\circ} \mathrm{C}$. During storage, the samples were thawed at room temp for $30 \mathrm{~min}$ and centrifuged to remove the top oil layer. The weight of the precipitated fraction $\left(\mathrm{F}_{1}\right)$ was measured, and the emulsion stability was characterized as $\%=\left(\mathrm{F}_{1}\right)$ $\left.\mathrm{F}_{0}\right) \times 100$.

\section{Sensory evaluation}

Sensory evaluation was conducted after one-day storage at room temperature. Sensory characteristics including appearance, color, odor, mouthfeel, taste, and overall acceptance were evaluated by 10 trained panelists on a 9 -point hedonic scale $(1=$ dislike the most; $9=$ like the most).

\section{Statistical analysis}

All the tests were performed in triplicate, and results were expressed as mean \pm standard deviation. A one-way analysis of variance (ANOVA) and Duncan's multiple range tests were used to establish the significance $(\mathrm{p}<0.05)$ of differences. The result was analyzed using the SAS vision 9.2 software program (SAS Institute, Cary, NC, USA).

\section{RESULTS AND DISCUSSION}

\section{Physicochemical properties of RFMs with native and modified rice starches}

The plan the experiment was to test the suitability of rice starches as fat substitute or fat mimetic in reducedfat mayonnaise formulations. Starches substituted for oil in formulations to the maximum possible extent that doesn't adversely affect their physicochemical and sensory properties. Gums co-addition (up to $10 \%$ ) was intended mainly to impart optimal viscosity to the reduced-fat mayonnaise formulations. Initially we tried starch gels (native and modified) substitution at 10-50\% levels (full data not shown). The short notations of the mayonnaise formulations developed for this study are given in Table 2 .

As shown in Table 3, a slight but significant decrease in $\mathrm{pH}$ was observed in reduced-fat mayonnaises with native starch gel at 10\% level and modified starch gels, both hydroxypropylated and cross-linked hydroxypropylated, at $20 \%$ level. And, a remarkable decrease in viscosity was noted in reduced-fat (RF) mayonnaises upon rice starch gel substitution. Viscosity decreased linearly with increasing amount of starch substitution. Compared to FFM viscosity, over 3- and 5-fold viscosity reductions were observed for RS30 and RS50, respectively. However at 10\% level, insignificant $(p>0.05)$ change of viscosity was observed.

In native or unmodified form, starches have limited use in the food industry. In general, native starches produce weak-bodied, cohesive, rubbery pastes when heated and undesirable gels when the pastes are cooled (Abbas et al., 2010). In order to meet its intended function, physical, chemical or enzymatic modifications are applied to achieve the functional properties not found in native starches (Dura et al., 2014). Modifications to starch improve its water holding capacity, heat resistant behavior, reinforce its binding, and improved thickening (Miyazaki et al., 2006).

In this study, native rice starch is chemically modified to hydroxypropylated and cross-linked hydroxypropylated starches. Substitution of cross-linked hydroxypropylated starch gel at 20\% level in RCHS20 has shown moderate benefit in terms of improved viscosity retention, compared to the other two starches substitution, as shown in Table 3.

\begin{tabular}{|c|c|}
\hline Short notation & Expanded form \\
\hline FFM & Full-fat mayonnaise \\
\hline RFM & Reduced-fat mayonnaise \\
\hline $\begin{array}{l}\text { RS10, RS20, } \\
\text { RS30 and } \\
\text { RS50 }\end{array}$ & $\begin{array}{l}\text { Reduced-fat mayonnaises with rice starch (native) } \\
\text { gel substituted at a level of } 10,20,30 \text { and } 50 \% \text { of } \\
\text { total oil, respectively }\end{array}$ \\
\hline RHS20 & $\begin{array}{l}\text { Reduced-fat mayonnaise with hydroxypropylated } \\
\text { rice starch gel substituted at a level } 20 \% \text { of total oil }\end{array}$ \\
\hline RCHS20 & $\begin{array}{l}\text { Reduced-fat mayonnaise with cross-linked } \\
\text { hydroxypropylated rice starch gel substituted at a } \\
\text { level } 20 \% \text { of total oil }\end{array}$ \\
\hline $\begin{array}{l}\text { RS20G, } \\
\text { RS30G and } \\
\text { RS40G }\end{array}$ & $\begin{array}{l}\text { Reduced-fat mayonnaises with rice starch (native) } \\
\text { gel substituted at a level of } 20,30 \text { and } 40 \% \text { of total } \\
\text { oil, respectively }+10 \% \text { guar gum in each }\end{array}$ \\
\hline $\begin{array}{l}\text { RS20X, RS30X } \\
\text { and RS40X }\end{array}$ & $\begin{array}{l}\text { Reduced-fat mayonnaises with rice starch (native) } \\
\text { gel substituted at a level of } 20,30 \text { and } 40 \% \text { of total } \\
\text { oil, respectively }+10 \% \text { xanthan gum in each }\end{array}$ \\
\hline
\end{tabular}


However, the viscosity of RCHS20 mayonnaise was still significantly $(\sim 50 \%)$ lower than FFM.

Instrumental color characteristics of reduced-fat mayonnaise formulations and FFM were comparatively studied. The brightness ( $\mathrm{L}^{*}$ value) and redness ( $\mathrm{a}^{*}$ value) of RF mayonnaises were increased with increasing level of starch substitution (Table 3). Compared to FFM control sample, all the tested reduced-fat mayonnaise formulations were appeared more shiny, yellowish-white sauces; and these changes were statistically significant $(p<0.05)$. A similar pattern was observed for redness. Whereas level of starch substitution and yellowness (b* value) in RF mayonnaises were inversely related. In general, $\mathrm{L}^{*}$ and $b^{*}$ values are inversely related (Kruger et al., 1992). However, yellowness reduction was insignificant at the $20 \%$ level, both with native and modified starches. From these results, rice starch gel substitution up to $20 \%$ of total oil was found optimal.

\section{Sensory properties of RFMs with native and modified rice starches}

Sensory evaluation scores of the FF and RF mayonnaises are shown in Table 4. The appearance of all the formulated reduced-fat mayonnaises was better than FFM control except RS50, wherein starch gel substitution at $50 \%$ of total oil has significantly $(p<0.05)$ negatively affected its appearance. Appearance was a bit thin in RS50. Other sensory scores of RS50 such as color, odor, taste and mouthfeel were more or less equal to control, and these changes were insignificant. The overall acceptability of reduced-fat mayonnaises was significantly $(\mathrm{p}<0.05)$ better than control except for RS50, which has a similar sensory score to control. Modified starch gels addition at 20\% level did not alter the sensory characteristics of reducedfat mayonnaises.

\section{Freeze-thaw stability of RFMs with native and modified rice starches}

We determined the freeze-thaw stability of reduced-fat mayonnaises formulated using starch gels at $20 \%$ level. As shown in Fig.1, freeze-thaw stability decreases with storage time. In the FFM (control), a rapid decrease of stability was observed, about $50 \%$ reduction in 4 days of storage. On the contrary, RS20, RHS20 and RCHS20 mayonnaises exhibited relatively stable emulsion stability; especially, a significant improvement $(\mathrm{p}<0.05)$ has noted with the addition of cross-linked, hydroxypropylated rice starch gel. This clearly indicates that both native and modified starch gels addition at 20\% level has a positive and highly significant effect on freeze-thaw stability of reduced-fat mayonnaises.

\section{Effects of gum addition on the characteristics of RFMs with native rice starch}

Gum gels, guar or xanthan, addition at 10\% along with rice starch gels at different (20-40\%) levels has no impact on $\mathrm{pH}$ of the formulated reduced-fat mayonnaises, as shown in Table 5. Both the gums along with starches aided in better viscosity retention in RS40G and RS40X mayonnaises, in which starch gel was substituted at $40 \%$, than using starches alone. However, gums co-addition with starches had no positive effect on viscosity retention in RS20G, RS30G, RS20X and RS30X. This variation in viscosity retention

Table 3: Physicochemical properties of reduced-fat mayonnaises with different levels of native and modified rice starches

\begin{tabular}{|c|c|c|c|c|c|}
\hline \multirow[t]{2}{*}{ Mayonnaise } & \multirow[t]{2}{*}{$\mathrm{pH}$} & \multirow{2}{*}{$\begin{array}{c}\text { Viscosity } \\
\text { (mPas) }\end{array}$} & \multicolumn{3}{|c|}{ Color values } \\
\hline & & & L*(brightness) & $a^{*}($ redness) & $\mathbf{b}^{*}$ (yellowness) \\
\hline Control & $3.71 \pm 0.10^{\mathrm{a}}$ & $2002.67 \pm 264.37^{a}$ & $76.67 \pm 0.10^{c}$ & $-4.52 \pm 0.05^{c}$ & $19.95 \pm 0.47^{a}$ \\
\hline RS10 & $3.55 \pm 0.14^{b}$ & $1767.96 \pm 274.05^{a}$ & $80.86 \pm 0.87^{b}$ & $-3.67 \pm 0.28^{b}$ & $18.17 \pm 0.86^{b}$ \\
\hline RS30 & $3.71 \pm 0.03^{\mathrm{a}}$ & $621.19 \pm 89.65^{b}$ & $82.40 \pm 0.21^{a}$ & $-3.26 \pm 0.12^{a}$ & $17.39 \pm 0.76^{b}$ \\
\hline RS50 & $3.69 \pm 0.07^{a b}$ & $383.40 \pm 78.94^{b}$ & $82.84 \pm 0.70^{\mathrm{a}}$ & $-3.22 \pm 0.16^{a}$ & $17.36 \pm 0.74^{b}$ \\
\hline RS20 & $3.72 \pm 0.01^{\mathrm{a}}$ & $921.82 \pm 155.85^{b}$ & $82.37 \pm 0.26^{b}$ & $-3.35 \pm 0.27^{a}$ & $17.66 \pm 0.96^{a}$ \\
\hline RHS20 & $3.65 \pm 0.06^{b}$ & $856.18 \pm 76.22^{b}$ & $83.34 \pm 0.15^{\mathrm{a}}$ & $-3.27 \pm 0.28^{a}$ & $17.60 \pm 1.33^{a}$ \\
\hline RCHS20 & $3.67 \pm 0.01^{b}$ & $1187.32 \pm 31.08^{b}$ & $82.62 \pm 0.54^{\mathrm{ab}}$ & $-3.28 \pm 0.29^{a}$ & $17.78 \pm 1.33^{a}$ \\
\hline
\end{tabular}

Mean \pm standard deviation $(n=3)$. ${ }^{a-c}$ Means within a column followed by different letters are significantly different at $(p<0.05)$

Table 4: Sensory scores of reduced-fat mayonnaises with different levels of native and modified rice starches

\begin{tabular}{lcccccc}
\hline Mayonnaise & Appearance & Color & Odor & Taste & Mouthfeel & Overall acceptability \\
\hline Control & $6.41 \pm 0.80^{\mathrm{ab}}$ & $6.33 \pm 0.96^{\mathrm{a}}$ & $5.45 \pm 1.55^{\mathrm{a}}$ & $6.08 \pm 1.08^{\mathrm{a}}$ & $6.31 \pm 0.86^{\mathrm{a}}$ & $6.22 \pm 0.86^{\mathrm{b}}$ \\
RS10 & $7.31 \pm 0.98^{\mathrm{a}}$ & $7.26 \pm 0.87^{\mathrm{a}}$ & $6.33 \pm 1.39^{\mathrm{a}}$ & $6.67 \pm 1.39^{\mathrm{a}}$ & $7.07 \pm 1.24^{\mathrm{a}}$ & $7.14 \pm 0.89^{\mathrm{a}}$ \\
RS30 & $7.38 \pm 1.40^{\mathrm{a}}$ & $7.19 \pm 1.43^{\mathrm{a}}$ & $6.60 \pm 1.13^{\mathrm{a}}$ & $6.40 \pm 1.13^{\mathrm{a}}$ & $6.88 \pm 1.31^{\mathrm{a}}$ & $7.17 \pm 1.15^{\mathrm{a}}$ \\
RS50 & $5.98 \pm 1.50^{\mathrm{b}}$ & $6.73 \pm 1.39^{\mathrm{a}}$ & $6.45 \pm 1.23^{\mathrm{a}}$ & $5.57 \pm 1.25^{\mathrm{a}}$ & $5.90 \pm 1.34^{\mathrm{a}}$ & $5.95 \pm 1.18^{\mathrm{b}}$ \\
RS20 & $6.76 \pm 1.15^{\mathrm{a}}$ & $7.30 \pm 0.85^{\mathrm{a}}$ & $6.94 \pm 0.55^{\mathrm{a}}$ & $7.02 \pm 1.14^{\mathrm{a}}$ & $6.66 \pm 0.64^{\mathrm{a}}$ & $7.35 \pm 1.00^{\mathrm{a}}$ \\
RHS20 & $7.07 \pm 0.82^{\mathrm{a}}$ & $7.30 \pm 0.63^{\mathrm{a}}$ & $7.11 \pm 0.62^{\mathrm{a}}$ & $7.11 \pm 0.86^{\mathrm{a}}$ & $7.09 \pm 0.62^{\mathrm{a}}$ & $7.49 \pm 0.94^{\mathrm{a}}$ \\
RCHS20 & $6.93 \pm 0.69^{\mathrm{a}}$ & $7.03 \pm 0.83^{\mathrm{a}}$ & $6.85 \pm 0.76^{\mathrm{a}}$ & $6.64 \pm 0.95^{\mathrm{a}}$ & $6.57 \pm 0.98^{\mathrm{a}}$ & $6.94 \pm 0.78^{\mathrm{a}}$ \\
\hline
\end{tabular}

Mean \pm standard deviation $(n=3)$. ${ }^{a-b}$ Means within a column followed by different letters are significantly different at $(p<0.05)$ 
could be due to changes in starch/gum ratio, which in turn affects the gelling process of starch/gum mixed sytems. Regarding the color values, compared to control, brightness and redness were significantly $(p<0.05)$ high up on starchgum mixtures substitution in all formulated reduced-fat mayonnaises. And, yellowness relatively reduced as usual with higher $\mathrm{L}^{*}$ value.

\section{Effect of gums addition on sensory characteristics}

Gum gels were added at a level of 10\%. Co-addition of either guar or xanthan gum along with starch gel at $20 \%$ exhibited significant positive impact on appearance and color of reduced-fat mayonnaises compared to control; xanthan gum showed more positive effect than guar gum

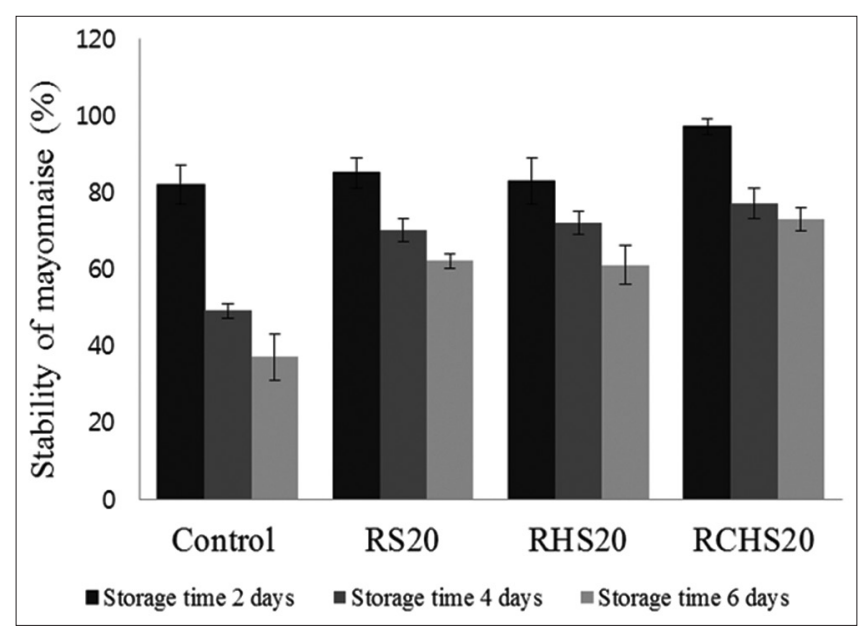

Fig 1. Freeze-thaw stability of reduced-fat mayonnaise substituted with native and modified rice starch gels for oil. on these two parameters (Table 6). On the contrary, with both 20 and 30\% starch gels co-substitution, guar gum exhibited a more positive effect in terms of better odor and taste than xanthan gum. Mouthfeel was improved with gum-starch mixture addition; mouthfeel of RS20X was significantly higher than the control one. The overall acceptability of all the formulated reduced-fat mayonnaises was significantly greater than control mayonnaise.

\section{CONCLUSIONS}

In conclusion, both native and modified rice starches are equally suitable for fat substitution while formulating reduced-fat mayonnaises. However, modified starches outperformed native starch in terms of freeze-thaw stability of mayonnaise. Compared to control, significantly better sensory characteristics were noted with starch substitution in reduced-fat mayonnaises. Xanthan or guar gums addition along with starch showed a bit positive impact on viscosity retention. The gum gels substitution at 10\% for oil had no adverse effect on the sensory characteristics of reducedfat mayonnaises. From these results, it can be concluded that both native and modified rice starches can potentially be used to replace oil up to $50 \%$ for the formulation of reduced-fat mayonnaises.

\section{ACKNOWLEDGMENTS}

This work was supported by a grant from IPET, Ministry of Agriculture, Food and Rural Affairs, Republic of Korea.

Table 5: Physicochemical properties of reduced-fat mayonnaises substituted with gums (guar gum, xanthan gum) and different levels of rice starch

\begin{tabular}{|c|c|c|c|c|c|}
\hline \multirow[t]{2}{*}{ Starch } & \multirow[t]{2}{*}{$\mathrm{pH}$} & \multirow{2}{*}{$\begin{array}{l}\text { Viscosity } \\
\text { (mPas) }\end{array}$} & \multicolumn{3}{|c|}{ Color values } \\
\hline & & & $L^{*}$ & $a^{*}$ & $\mathbf{b}^{*}$ \\
\hline Control & $3.71 \pm 0.10^{a}$ & $2002.67 \pm 264.10^{a}$ & $76.67 \pm 0.10^{b}$ & $-4.52 \pm 0.05^{c}$ & $19.95 \pm 0.47^{a}$ \\
\hline RS20G & $3.72 \pm 0.12^{\mathrm{a}}$ & $787.13 \pm 65.12^{\mathrm{bc}}$ & $83.27 \pm 0.55^{a}$ & $-3.11 \pm 0.05^{a}$ & $16.00 \pm 0.19^{c}$ \\
\hline RS30G & $3.76 \pm 0.07^{a}$ & $661.42 \pm 124.65^{c}$ & $83.58 \pm 0.45^{a}$ & $-3.12 \pm 0.06^{a}$ & $16.17 \pm 0.32^{c}$ \\
\hline RS40G & $3.71 \pm 0.08^{a}$ & $603.46 \pm 197.25^{\circ}$ & $83.78 \pm 0.49^{a}$ & $-3.18 \pm 0.09^{a b}$ & $16.21 \pm 0.37^{\circ}$ \\
\hline RS20X & $3.71 \pm 0.04^{\mathrm{a}}$ & $1025.12 \pm 81.21^{b}$ & $82.97 \pm 0.33^{a}$ & $-3.34 \pm 0.11^{\mathrm{ab}}$ & $17.20 \pm 0.28^{b}$ \\
\hline RS30X & $3.71 \pm 0.07^{a}$ & $555.32 \pm 131.65^{c}$ & $83.42 \pm 0.20^{\mathrm{a}}$ & $-3.30 \pm 0.19^{a b}$ & $17.08 \pm 0.66^{b}$ \\
\hline RS40X & $3.74 \pm 0.05^{a}$ & $509.82 \pm 152.33^{c}$ & $83.75 \pm 0.67^{a}$ & $-3.42 \pm 0.13^{b}$ & $17.57 \pm 0.66^{b}$ \\
\hline
\end{tabular}

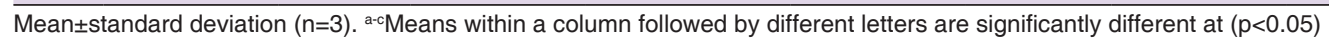

Table 6: Sensory scores of mayonnaise substituted with native rice starch and gums for oil

\begin{tabular}{lcccccc}
\hline Starch & Appearance & Color & Odor & Taste & Mouthfeel & Overall acceptability \\
\hline Control & $6.41 \pm 0.80^{\mathrm{ab}}$ & $6.33 \pm 0.96^{\mathrm{c}}$ & $5.45 \pm 1.55^{\mathrm{b}}$ & $6.08 \pm 1.08^{\mathrm{a}}$ & $6.31 \pm 0.86^{\mathrm{b}}$ & $6.22 \pm 0.86^{\mathrm{c}}$ \\
RS20G & $7.08 \pm 0.83^{\mathrm{a}}$ & $7.35 \pm 0.67^{\mathrm{ab}}$ & $7.55 \pm 0.52^{\mathrm{a}}$ & $7.32 \pm 1.10^{\mathrm{a}}$ & $7.20 \pm 0.98^{\mathrm{ab}}$ & $7.17 \pm 0.87^{\mathrm{ab}}$ \\
RS30G & $6.60 \pm 0.81^{\mathrm{ab}}$ & $7.18 \pm 0.75^{\mathrm{ab}}$ & $7.47 \pm 0.65^{\mathrm{a}}$ & $7.28 \pm 0.65^{\mathrm{a}}$ & $6.93 \pm 0.80^{\mathrm{b}}$ & $7.09 \pm 0.30^{\mathrm{ab}}$ \\
RS40G & $6.07 \pm 0.94^{\mathrm{b}}$ & $7.06 \pm 0.85^{\mathrm{b}}$ & $7.27 \pm 0.52^{\mathrm{a}}$ & $6.58 \pm 1.07^{\mathrm{a}}$ & $6.55 \pm 1.04^{\mathrm{b}}$ & $6.44 \pm 0.47^{\mathrm{c}}$ \\
RS20X & $7.50 \pm 1.00^{\mathrm{a}}$ & $7.67 \pm 0.65^{\mathrm{a}}$ & $7.42 \pm 0.51^{\mathrm{a}}$ & $7.17 \pm 1.19^{\mathrm{a}}$ & $7.75 \pm 1.06^{\mathrm{a}}$ & $7.58 \pm 0.87^{\mathrm{a}}$ \\
RS30X & $7.33 \pm 0.78^{\mathrm{a}}$ & $7.58 \pm 0.51^{\mathrm{ab}}$ & $7.33 \pm 0.75^{\mathrm{a}}$ & $7.08 \pm 1.16^{\mathrm{a}}$ & $7.00 \pm 0.60^{\mathrm{b}}$ & $7.38 \pm 0.61^{\mathrm{a}}$ \\
RS40X & $6.63 \pm 1.07^{\mathrm{ab}}$ & $7.21 \pm 0.66^{\mathrm{ab}}$ & $7.25 \pm 0.66^{\mathrm{a}}$ & $6.75 \pm 1.14^{\mathrm{a}}$ & $6.92 \pm 0.79^{\mathrm{b}}$ & $7.00 \pm 0.60^{\mathrm{ab}}$ \\
\hline
\end{tabular}

Mean \pm standard deviation $(n=3) .{ }^{a-c}$ Means within a column followed by different letters are significantly different at $(p<0.05)$ 


\section{Author contributions}

P. P. was involved in literature collection, sample analysis and manuscript preparation, Y. C. was involved in conducting experiments, Y. L. was involved in designing the study, supervised the research project.

\section{REFERENCES}

Abbas, K. A., S. K. Khalil and A. S. Meor Hussin. 2010. Modified starches and their usages in selected food products: A review study. J. Agric. Sci. 2: 90-100.

Bortnowska, G. and G. Tokarczyk. 2009. Comparison of the physical and sensory properties of model low-fat mayonnaises depending on emulsifier type and xanthan gum concentration. Electron. J. Pol. Agric. Univ. 12: 11.

Cheung, I., F. Gomes, R. Ramsden and D. G. Roberts. 2002. Evaluation of fat replacers Avice ${ }^{\mathrm{Tm}}, \mathrm{N}^{\mathrm{L}}$ ite $\mathrm{S}^{\mathrm{TM}}$ and Simplesse $^{\mathrm{TM}}$ in mayonnaise. Int. J. Consum. Stud. 26: 27-33.

Cho, S. J., H. S. Lim, H. J. Park, H. J. Hwang and S. T. Lim. 1999. Physical properties of octenyl succinylated corn amylodextrins as fat replacers in mayonnaise. Food Sci. Biotechnol. 8: 322-328.

Choi, H. W., S. H. Hong, S. W. Choi, C. N. Kim, S. S. Yoo, B. Y. Kim and M. Y. Baik. 2011. Physiochemical properties of dualmodified (cross-linked and hydroxypropylated) rice starches. Food Eng. Prog. 15: 382-397.

Dura, A., W. Błaszczak and C. M. Rosell. 2014. Functionality of porous starch obtained by amylase or amyloglucosidase treatments. Carbohydr. Polym. 101: 837-845.

El-Bostany, A. N., M. G. Ahmed and A. S. Amany. 2011. Development of light mayonnaise formula using carbohydrate-based fat replacement. Aust. J. Basic Appl. Sci. 5: 673-682.

Kruger, J. E., R. R. Matsuo and K. Preston. 1992. A comparison of methods for the prediction of Cantonese noodle colour. Can. J. Plant Sci. 72: 102l-1029.

Lee, I., S. Lee, N. Lee and S. Ko. 2013. Reduced-fat mayonnaise formulated with gelatinized rice starch and xanthan gum. Cereal Chem. 90: 29-34.

Liu, H., X. M. Xu and Sh. D. Guo. 2007. Rheological, texture and sensory properties of low-fat mayonnaise with different fat mimetics. LWT-Food Sci. Technol. 40: 946-954.

Lorenzo, G., N. Zaritzky and A. Califano. 2008. Modeling rheological properties of low-in-fat o/w emulsions stabilized with xanthan/ guar mixtures. Food Res. Int. 41: 487-494.

Ma, L. and G. V. Barbosa-Ca'novas. 1995. Rheological characterization of mayonnaise. Part II: Flow and viscoelastic properties at different oil and xanthan gum concentrations. J. Food Eng. 25: 409-425.

Miyazaki, M. R., P. V. Hung, T. Maeda and N. Morita. 2006. Recent advances in application of modified starches for breadmaking. Trends Food Sci. Tech. 17: 591-599.

Mun, S., Y. L. Kim, C. G. Kang, K. H. Park, J. Y. Shim and Y. R. Kim. 2009. Development of reduced-fat mayonnaise using 4aGTasemodified rice starch and xanthan gum. Int. J. Biol. Macromol. 44: 400-407.

Nikzade, V., M. Mazaheri Tehrani and M. Saadatmand-Tarzjan. 2012. Optimization of low-cholesterol - low-fat mayonnaise formulation: Effect of using soy milk and some stabilizer by a mixture design approach. Food Hydrocoll. 28: 344-352.

Pszczola, D. E. 1999. Starches and gums move beyond fat replacement. Food Technol. 53: 74-80.

Quintana, J. M., A. N. Califano, N. E. Zaritzky, P. Partal and J. M. Franco. 2002. Linear and nonlinear viscoelastic behavior of oil-in-water emulsions stabilized with polysaccharides. J. Texture Stud. 33: 215-236.

Su, H. P., C. P. Lien, T. A. Lee and J. H. Ho. 2010. Development of low-fat mayonnaise containing polysaccharide gums as functional ingredients. J. Sci. Food Agric. 90: 806-812.

Thaiudom, S. and K. Khantarat. 2011. Stability and rheological properties of fat-reduced mayonnaises by using sodium octenyl succinate starch as fat replacer. Procedia Food Sci. 1: 315-321.

Weber, F. H., M. T. P. S. Clerici, F. P. Collares-Queiroz and Y. K. Chang. 2009. Interaction of guar and xanthan gums with starch in the gels obtained from normal, waxy and high-amylose corn starches. Starch Stärke. 61: 28-34.

Weisburger, J. H. 1997. Dietary fat and risk of chronic disease: Mechanistic Insights from experimental studies. J. Am. Diet. Assoc. 97: s16-s23.

Wootton, M. and A. Manatsathit. 1984. The influence of molar substitution on the gelatinization of hydroxypropyl maize starches. Starch. 36: 207-208.

Worrasinchai, S., M. Suphantharika, S. Pinjai and P. Jamnong. 2006. $\beta$-Glucan prepared from spent brewer's yeast as a fat replacer in mayonnaise. Food Hydrocoll. 20: 68-78.

Yamamoto, K., S. Sawada and T. Onogaki. 1973. Properties of rice starch prepared by alkali method with various conditions. Denpun Kagaku. 20: 99-104. 